\title{
Anti-inhibitory potential of an ethanolic extract of Distromium decumbens on pro-inflammatory cytokine production in Pseudomonas aeruginosa lipopolysaccharide-stimulated nasal polyp-derived fibroblasts
}

\author{
DAE-SUNG LEE ${ }^{1 *}$, CHANG-MIN LEE $^{2 *}$, SEONG KOOK PARK ${ }^{3}$, MI-JIN YIM $^{1}$, JEONG MIN LEE ${ }^{1}$, \\ GRACE CHOI ${ }^{1}$, JONG SU YOO ${ }^{1}$, WON-KYO JUNG ${ }^{4}$, SAEGWANG PARK $^{5}$, \\ SU-KIL SEO ${ }^{5}$, WON SUN PARK ${ }^{6}$ and IL-WHAN CHOI ${ }^{5}$

\begin{abstract}
${ }^{1}$ Department of Applied Research, National Marine Biodiversity Institute of Korea, Seocheon 33662, Republic of Korea;
${ }^{3}$ Department of Otorhinolaryngology-Head and Neck Surgery, Inje University College of Medicine, Busan Paik Hospital, Busan 47392; ${ }^{4}$ Department of Biomedical Engineering, and Center for Marine-Integrated Biomedical Technology

(BK21 Plus), Pukyong National University, Busan 48513; ${ }^{5}$ Department of Microbiology and Immunology,

College of Medicine, Inje University, Busan 47392; ${ }^{6}$ Department of Physiology,

Kangwon National University School of Medicine, Chuncheon 24341, Republic of Korea
\end{abstract} \\ ${ }^{2}$ Department of Molecular Microbiology and Immunology, Warren Alpert School of Medicine, Providence, RI 02912, USA;
}

Received November 2, 2016; Accepted August 31, 2017

DOI: $10.3892 /$ ijmm.2017.3182

\begin{abstract}
Marine algae are rich sources of biologically active compounds that may present useful leads in the development of pharmaceuticals, nutraceuticals, and functional foods. The main aim of this study was to identify the possible antiinflammatory effects of Distromium decumbens in nasal polyp-derived fibroblasts (NPDFs) and its associated mechanism of action. NPDFs were stimulated by Pseudomonas aeruginosa lipopolysaccharide (PA-LPS) and treated with an ethanolic extract of Distromium decumbens (DDE). The production of interleukin-6 (IL-6) and IL-8 in the supernatant, the phosphorylation of mitogen-activated protein kinase (MAPK) molecules [extracellular signal-related kinase 1/2 (ERK1/2), c-Jun N-terminal kinase and p38 MAPK] and $\mathrm{Akt}$, and the activation of nuclear factor- $\kappa \mathrm{B}(\mathrm{NF}-\kappa \mathrm{B})$ were assayed in the $P A$-LPS-stimulated NPDFs untreated or
\end{abstract}

Correspondence to: Professor Il-Whan Choi, Department of Microbiology and Immunology, College of Medicine, Inje University, Bokji-Ro 75, Busanjin-gu, Busan 47392, Republic of Korea

E-mail: cihima@inje.ac.kr

Professor Won Sun Park, Department of Physiology, Kangwon National University School of Medicine, 1 Kangwondaehak-gil, Chuncheon-si, Gangwon-do, Chuncheon 24341, Republic of Korea E-mail: parkws@kangwon.ac.kr

*Contributed equally

Key words: nasal polyps, Distromium decumbens, Pseudomonas aeruginosa lipopolysaccharide, inflammatory cytokines, neutrophils treated with DDE. The expression levels of IL-6 and IL-8 in $P A$-LPS-exposed NPDFs were detected using enzymelinked immlunosorbent assays. The mechanisms by which DDE regulates cellular signaling cascades were investigated using electrophoretic mobility shift assays and western blot analysis. Functional validation was performed by measuring the inhibitory effects of DDE on neutrophil migration in vitro. DDE reduced the expression of IL- 6 and IL- 8 stimulated by $P A$-LPS in NPDFs. The activation of ERK1/2, Akt and NF- $\kappa \mathrm{B}$ by $P A$-LPS was inhibited by DDE. Inhibitors of ERK1/2, Akt and NF- $\kappa$ B inhibited the expression of IL- 6 and IL-8. In addition, DDE significantly attenuated $P A$-LPS-induced migration of differentiated HL-60 cells. The present findings suggest that DDE potently inhibits inflammation through the ERK1/2, Akt and NF- $\kappa$ B signaling pathways in NPDFs.

\section{Introduction}

Nasal polyps (NPs) cause considerable morbidity, including nasal congestion, rhinorrhea, anosmia, decreased taste, sinusitis, olfactory dysfunction and headaches, which significantly deteriorate the quality of life of patients (1). NPs are swellings of the lining of the nasal passages and sinuses. They are characterized by tissue remodeling consisting of basement membrane thickening, goblet cell hyperplasia, epithelial proliferation, pseudocyst formation, focal fibrosis, inflammatory cell infiltration and edema $(1,2)$. NPs are a common chronic inflammatory disease of the mucous membranes with a high recurrence rate in the nose and paranasal sinuses, and are generally related with chronic rhinosinusitis (CRS) (3). While many studies on NPs have been carried out, the pathogenesis of NPs has not been elucidated thus far. 
Many types of cells, such as epithelial cells, T cells, mast cells and fibroblasts, are related with the pathogenesis of NPs (3). Among these, fibroblasts are the critical component of the polyp organization. Fibroblasts are relevant regulators of local inflammation due to a source of biological mediators in initiating and amplifying inflammation (4). Stimulated fibroblasts contribute towards the inflammatory response by releasing inflammatory mediators. Pseudomonas aeruginosa (P.aeruginosa) can be frequently found in nasal smears of patients with persistent sinus symptoms after sinus surgery (5). Previous studies have shown that lipopolysaccharide (LPS) derived from $P$. aeruginosa induces interleukin-1 (IL-1), IL-6, monocyte chemoattractant protein-1 (MCP-1), and tumor necrosis factor- $\alpha$ (TNF- $\alpha$ ) in airway inflammation and goblet cell hyperplasia (6). Among these inflammatory mediators, IL-6 and IL- 8 were found to be produced in LPS-stimulated NP-derived fibroblasts (NPDFs) (4). NPDF activation by LPS appears to play a crucial role in the initiation and progression of NPs. Therefore, regulation of NPDF activation and inhibition of these inflammatory mediators may be therapeutic targets to reduce the development of NPs.

Marine algae have been used as dietary and medicinal component in Asia and are rich in dietary fibers, minerals, vitamins, polysaccharides, proteins and various functional polyphenols (7). Previous studies have supported the pharmaceutical and the medicinal importance of seaweed in treating NFs $(7,8)$. The authors of the present study have found that the ethanolic extract of Distromium decumbens (DDE) has the highest quantity of total polyphenol content $(21.27 \pm 0.09 \%)$. In our previous study, DDE was found to have more than $89.57 \pm 0.43 \%$ 1,1-diphenyl-2-picrylhydrazyl radical scavenging activity (9). In addition, DDE inhibited nitric oxide, reactive oxygen species, and prostaglandin $\mathrm{E}_{2}$ production in RAW cells when LPS was used as an inducer (unpublished data). These inflammatory mediators serve important roles in inflammation-related disorders. Taken together, these results address the hypothesis that DDE may exert anti-inflammatory effects in NPs.

Therefore, as a part of our ongoing study to screen and evaluate the anti-inflammatory efficacy of natural bioactive materials, we focused on the anti-inflammatory effects of DDE and the mechanism related in NPDFs, which can be stimulated using LPS to mimic the conditions of NPs in vitro.

\section{Materials and methods}

Reagents. LPS from $P$. aeruginosa (PA-LPS) was purchased from Merck Millipore (Darmstadt, Germany). An antibody against nuclear factor- $\kappa \mathrm{B}(\mathrm{NF}-\kappa \mathrm{B})$ (cat. no. 14-6731) was purchased from eBioscience (San Diego, CA, USA). Antibodies against phospho (p)-extracellular signal-related kinase (ERK) (cat. no. 9106), c-Jun N-terminal kinase (JNK) (cat. no. 9252), p-JNK (cat. no. 9251), p-p38 mitogen-activated protein kinase (MAPK) (cat. no. 9211), Akt (cat. no. 9272), and p-Akt (cat. no. 4058) were purchased from Cell Signaling Technology, Inc. (Danvers, MA, USA). Antibodies against ERK (cat. no. sc-94), and p38 MAPK (cat. no. sc-535) were purchased from Santa Cruz Biotechnology, Inc. (Santa Cruz, CA, USA). Inhibitors of ERK kinase (U0126) and Akt (LY294002) were purchased from Calbiochem (Billerica, MA, USA) and were dissolved in dimethyl sulfoxide (DMSO).
BAY 11-7082 and parthenolide were purchased from Santa Cruz Biotechnology, Inc..

Preparation of ethanol extract from D. decumbens. Marine brown alga, D. decumbens, was collected from the Jeju Island, Korea. After collection, D. decumbens was washed with tap water to remove slats, epiphytes, and sand attached to the surface of the samples, and they were then maintained at $-20^{\circ} \mathrm{C}$. The samples were lyophilized and homogenized using a grinder. The dried powder was extracted with $70 \% \mathrm{EtOH}$ $(1: 10 \mathrm{w} / \mathrm{v})$ for $1 \mathrm{~h}$ (5 times) by sonication, and then the extract was evaporated in vacuo. The extract was dissolved in DMSO prior to use in the experiment.

NP-derived fibroblast culture. Fifteen subjects with NPs and 15 subjects with deviated nasal septum were recruited from the Department of Otorhinolaryngology, Inje University Busan Paik Hospital, Busan, Republic of Korea. Based on the minimum criteria for chronic sinusitis with NPs, individuals were diagnosed as having NPs (10). All patients who participated in this study provided informed consent and the procedure was approved by our local ethics committee. A NP was defined as the presence of an endoscopically visible bilateral polyp growing from the middle nasal meatus into the nasal cavity, and affecting the ethmoid and maxillary sinuses as observed using computed tomography of the paranasal sinus. NPs were obtained from the region of the middle meatus at the beginning of the surgical procedure. The subjects had no history of nasal allergy, aspirin sensitivity or asthma. No patient had prescribed steroids (topical or systemic), nonsteroidal anti-inflammatory drugs, antihistamines, or macrolide antibiotics during the 4 weeks before the biopsy. NPDFs were separated from tissues by enzymatic treatment with collagenase (500 U/ml), hyaluronidase (30 U/ml), and DNase (10 U/ml) (all from Sigma-Aldrich, St. Louis, MO, USA). Dulbecco's modified Eagle's medium was applied to culture the cells containing $10 \%(\mathrm{v} / \mathrm{v})$ heat-inactivated fetal bovine serum (Thermo Fisher Scientific, Inc., Waltham, MA, USA), 1,000 $\mu \mathrm{g} / \mathrm{ml}$ streptomycin (Invitrogen, Carlsbad, CA, USA), and 1,000 U/ml penicillin. The purity of the NPDFs was confirmed by flow cytometry and characteristic spindle-shaped cell morphology. Experimental cells were used in the fourth cell passage.

Cell line culture. RPMI-1640 medium supplemented with fetal bovine serum (10\%) was used to maintain HL-60 cells. To achieve the expression of the neutrophilic phenotype, the HL-60 cells were induced to differentiate (dHL-60) with $1.75 \%$ (vol/vol) DMSO for 3-4 days.

Determination of cell viability. The Cell Counting Kit-8 (CCK-8; Dojindo Laboratories, Kumamoto, Japan) method was applied to determine the cellular viability. Briefly, wells $\left(1 \times 10^{5}\right.$ cells $\left./ \mathrm{ml}\right)$ were incubated with DDE for $24 \mathrm{~h}$ and then the cells were washed with PBS twice. CCK- 8 was added to each well and incubated at $37^{\circ} \mathrm{C}$ for $1 \mathrm{~h}$, followed by analysis at $450 \mathrm{~nm}$ using a plate reader (model EL800; Bio-Tek Instruments, Inc., Winooski, VT, USA).

Enzyme-linked immunosorbent assay (ELISA). The cytokine levels in the culture media were detected using ELISA. ELISA 
kits, which were used to measure IL-6 and IL-8 expression levels, were purchased from BioLegend (San Diego, CA, USA). The absorbance at $450 \mathrm{~nm}$ was measured using a plate reader (model EL800; Bio-Tek Instruments, Inc.).

Cell migration assay. The dHL-60 cell migration was measured using a 24-well plate system at densities of $1 \times 10^{6}$ cells $/ \mathrm{ml}$. The dHL-60 cells were added to the upper chambers of Transwell cluster plates (24-well companion plate; BD Biosciences, Franklin Lakes, NJ, USA) with $3-\mu \mathrm{m}$ pore filters. PA-LPSinduced NPDFs were added to the lower wells of the plates. The cells were allowed to migrate for $24 \mathrm{~h}$ at $37^{\circ} \mathrm{C}$ in $5 \% \mathrm{CO}_{2}$. The transferred cells from the lower chamber were collected and then centrifuged at $400 \mathrm{x}$ g for $10 \mathrm{~min}$. The number of cells that had migrated to the lower well was counted with a hemocytometer. Each experiment was performed in triplicate and repeated at least 3 times.

Western blot analysis. The cells were lysed with lysis buffer (Mammalian Cell-PE LB; G-Biosciences, St. Louis, MO, USA). Equal amounts of protein were separated on $10 \%$ SDS-polyacrylamide mini-gels and transferred onto nitrocellulose membranes (GE Healthcare Life Sciences, Chalfont, UK). Following incubation with the appropriate primary antibodies (ERK, p-ERK, p38, p-p38, JNK, p-JNK, Akt, p-Akt and NF-кB) at a dilution of $1: 1,000$ overnight at $4^{\circ} \mathrm{C}$, the membranes were incubated with horseradish peroxidase conjugated anti-rabbit (cat. no. 31460; Pierce Biotechnology, Inc., Rockford, IL, USA) or anti-mouse (cat. no. sc-2031; Santa Cruz Biotechnology, Inc.) secondary antibodies. Following three washing with Trisbuffered saline Tween-20 (TBST), immunoreactive bands were visualized using an enhanced chemiluminescence (ECL) detection system (Pierce Biotechnology, Inc.).

Electrophoretic mobility shift assay (EMSA). Nuclear extract was prepared using the NE-PER nuclear extraction reagent (Pierce Biotechnology, Inc.). An oligonucleotide containing the immunoglobulin $\kappa$-chain binding site $(\kappa \mathrm{B}, 5$ '-GATCTCAGA GGGGACTTTCCGAGAGA-3') was synthesized as a probe for the gel retardation assay. A non-radioactive method, in which the $3^{\prime}$ end of the probe was labeled with biotin, was used (Pierce Biotechnology, Inc.). The binding reactions contained $5 \mu \mathrm{g}$ nuclear extract protein, buffer (10 mM Tris, $\mathrm{pH} 7.5,50 \mathrm{mM}$ $\mathrm{KCl}, 5 \mathrm{mM} \mathrm{MgCl}_{2}, 1 \mathrm{mM}$ dithiothreitol, $0.05 \%$ Nonidet P-40, and $2.5 \%$ glycerol $), 50 \mathrm{ng}$ poly (dI-dC) and $20 \mathrm{fM}$ biotin-labeled DNA. The reactions were incubated at room temperature for $20 \mathrm{~min}$ to a final volume of $20 \mu \mathrm{l}$. The competition reactions were performed by adding a 100 -fold excess of unlabeled $\kappa \mathrm{B}$ to the reaction mixture. The mixture was then separated by electrophoresis on a $5 \%$ polyacrylamide gel in $0.5 \mathrm{X}$ Tris-borate buffer and transferred to nylon membranes. The biotin-labeled DNA was assessed using a LightShift Chemiluminescent EMSA kit (Pierce Biotechnology, Inc.).

Statistical analysis. Data values represent the means \pm standard deviation. To analyze the data produced from the experiments with two independent variables, one-way analysis of variance was performed using GraphPad Prism software (GraphPad Software, Inc., La Jolla, CA, USA). Values of $\mathrm{P}<0.05$ and $\mathrm{P}<0.01$ were considered significant.

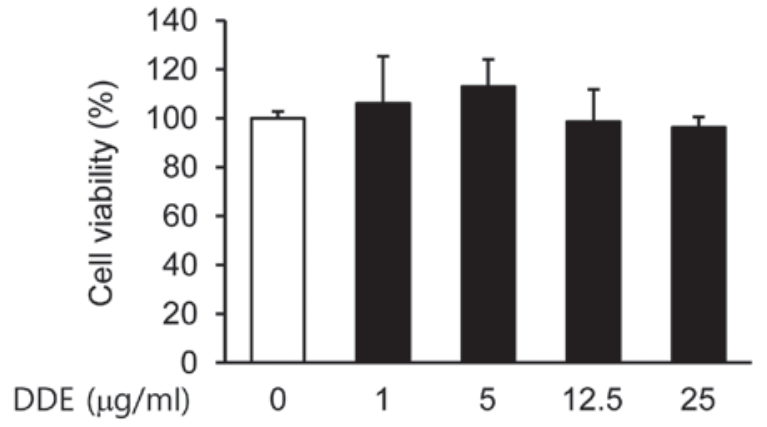

Figure 1. Effect of Distromium decumbens (DDE) on the viability of nasal polyp-derived fibroblasts (NPDFs). The cells were pretreated with the indicated concentrations of DDE $(1-25 \mu \mathrm{g} / \mathrm{ml})$ for $24 \mathrm{~h}$. Cell viability was examined using the Cell Counting Kit-8 (CCK-8) assay, and the results are expressed as the percentage of surviving cells compared to control cells (DMSO). Each value indicates the mean \pm standard deviation and represents results obtained from three independent experiments.

\section{Results}

Effects of DDE on the viability of NPDFs. Initially, we examined the viability of NPDFs treated with DDE by using a CCK-8 assay. No significant cytotoxicity to NPDFs was observed at doses up to $25 \mu \mathrm{g} / \mathrm{ml}$ (Fig. 1). Based on these results, a concentration range of 1 to $25 \mu \mathrm{g} / \mathrm{ml}$ was selected for the subsequent experiments.

Effects of DDE on the expression of $I L-6$ and $I L-8$ in $P A-L P S$-induced NPDFs. The protein expression levels of IL-6 and IL- 8 were markedly increased after the stimulation of NPDFs with PA-LPS (Fig. 2). To assess the effect of DDE on the protein production of IL-6 and IL-8 in NPDFs, we pretreated the cells with $\operatorname{DDE}(1,5,12.5$ and $25 \mu \mathrm{g} / \mathrm{ml})$ before stimulation with PA-LPS $(10 \mu \mathrm{g} / \mathrm{ml})$. The treatment with DDE attenuated the LPS-induced expression of IL- 6 and IL-8 proteins.

Effects of DDE on the migration of dHL-60 cells towards PA-LPS-stimulated NPDFs. To examine whether DDE affects the migration of dHL-60 cells, migration assays were performed using Transwell cluster plates (Fig. 3). The number of migrated dHL-60 cells co-cultured with PA-LPS-treated NPDFs was 2 times greater than that of the vehicle-treated dHL-60 cells. However, the levels of infiltration of the dHL-60 cells were significantly attenuated by DDE treatment in a concentration-dependent manner when compared with the infiltration of the $P A$-LPS-induced group.

Effects of DDE on the activation of the Akt and MAPK signaling pathways in PA-LPS-induced NPDFs. To clarify the mechanisms underlying the effects of DDE on the expression of inflammatory mediators, we inspected the activation of Akt and MAPKs using western blot analysis. The stimulation of NPDFs with $P A$-LPS resulted in an increase in the phosphorylation of Akt and ERK, but not of JNK and p38. Pretreatment for $1 \mathrm{~h}$ with $\operatorname{DDE}(1,12.5$ and $25 \mu \mathrm{g} / \mathrm{ml})$ attenuated the phosphorylation of Akt and ERK induced by a 2-h incubation with $10 \mu \mathrm{g} / \mathrm{ml} P A$-LPS (Fig. 4A). To verify whether the Akt and ERK signaling pathways are involved in the expression of IL-6 

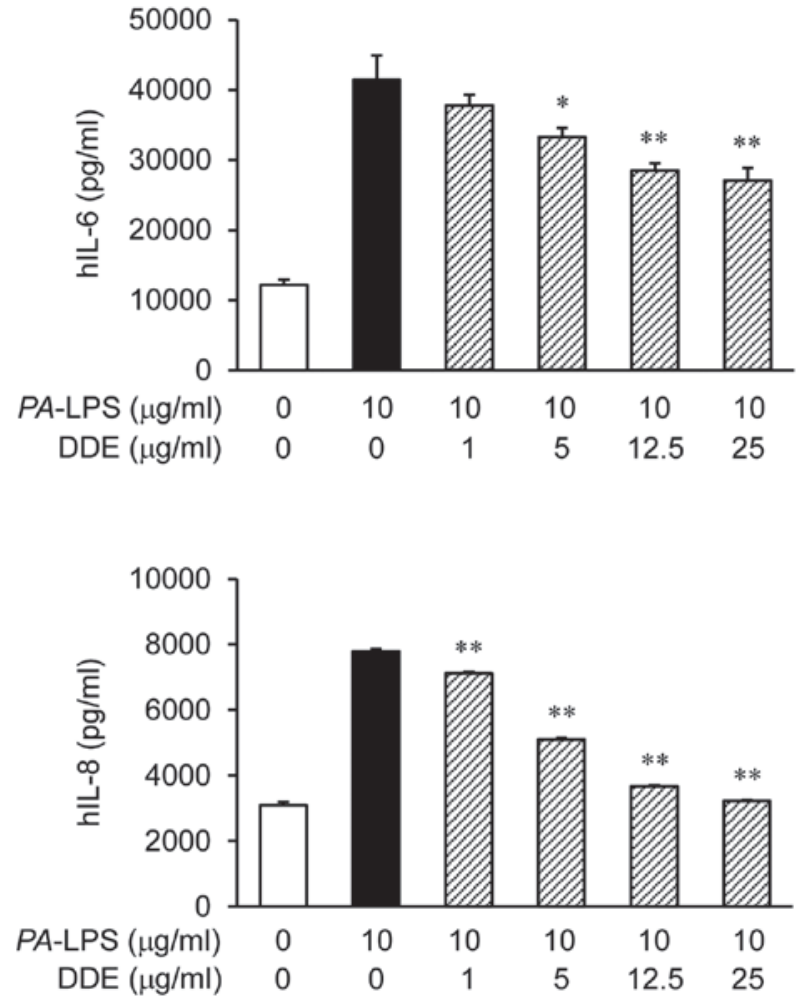

Figure 2. Effect of Distromium decumbens (DDE) on the expression of inflammatory cytokines in Pseudomonas aeruginosa-lipopolysaccharide (PA-LPS)-stimulated nasal polyp-derived fibroblasts (NPDFs). The expression levels of interleukin-6 (IL-6) and IL-8 proteins were determined by enzyme-linked immunosorbent assay (ELISA). The cells were pretreated with DDE $(1-25 \mu \mathrm{g} / \mathrm{ml})$ for $1 \mathrm{~h}$ prior to PA-LPS stimulation for $24 \mathrm{~h}$. Each bar represents the mean \pm standard deviation from three independent experiments. ${ }^{*} \mathrm{P}<0.05$ and ${ }^{* *} \mathrm{P}<0.01$ vs. $P A$-LPS-stimulated values.

and IL-8, NPDFs were treated with PA-LPS with or without DDE, Akt or ERK inhibitors. The upregulated expression of IL- 6 and IL-8 was significantly inhibited by U0126 (an inhibitor of ERK) and LY294002 (an inhibitor of Akt) (Fig. 4B).

Effects of DDE on the activation of NF- $\mathrm{B}$ in PA-LPSstimulated NPDFs. The production of pro-inflammatory cytokines is regulated by the transcription factor $\mathrm{NF}-\kappa \mathrm{B}$ in $P A$-LPS stimulation (11). Therefore, to inspect the mechanism by which DDE affects the expression of IL- 6 and IL-8, we assessed the effects of DDE on $\mathrm{NF}-\kappa \mathrm{B}$ activation. We found that DDE inhibited the $P A$-LPS-induced translocation of $\mathrm{NF}-\kappa \mathrm{B}$ p65 into the nuclear compartment (Fig. 5A). We next examined the effect of DDE on the DNA-binding activity of NF- $\kappa \mathrm{B}$ using EMSA (Fig. 5B). PA-LPS treatment caused a significant increase in the DNA-binding activity of $\mathrm{NF}-\kappa \mathrm{B}$, whereas treatment with DDE markedly reduced the $P A$-LPS-induced DNA-binding activity of NF- $\kappa \mathrm{B}$.

Effects of $N F-\kappa B$ inhibitors on the expression of $I L-6$ and IL-8 in PA-LPS-induced NPDFs. To confirm whether the $\mathrm{NF}-\kappa \mathrm{B}$ p65 signaling pathway is involved in the expression of IL-6 and IL-8, NPDFs were treated with PA-LPS with or without DDE or NF- $\mathrm{BB}$ inhibitors (BAY 11-7082 and parthenolide, respectively). As shown in Fig. 5C, BAY 11-7082 and

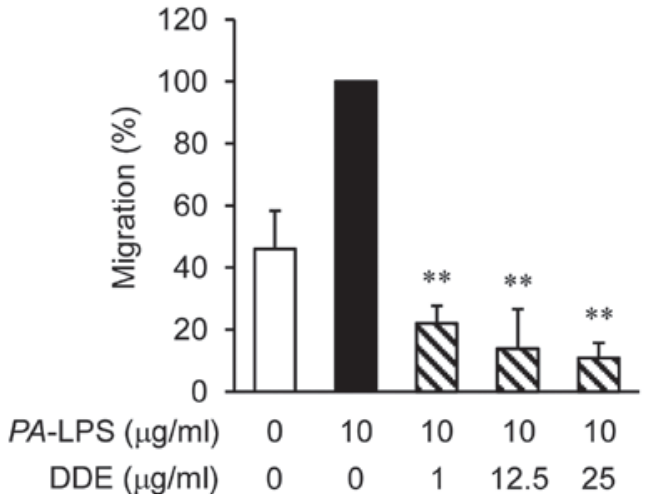

Figure 3. In vitro migration of dHL-60 cells. dHL-60 cells were added to the upper wells of Transwell cluster plates with $3 \mu \mathrm{m}$ pore filters. The cells were pretreated with Distromium decumbens (DDE) $(1-25 \mu \mathrm{g} / \mathrm{ml})$ for $1 \mathrm{~h}$ prior to Pseudomonas aeruginosa-lipopolysaccharide (PA-LPS) stimulation for $24 \mathrm{~h}$. $P A$-LPS-stimulated nasal polyp-derived fibroblasts (NPDFs) were added to the lower chambers of the plates. The numbers of cells that had migrated to the lower wells were counted using a hemocytometer. Each bar represents the mean \pm standard deviation from triplicates from three independent experiments. ${ }^{* *} \mathrm{P}<0.01$ vs. $P A$-LPS-stimulated values.

parthenolide inhibited the expression of IL-6 and IL-8 in the $P A$-LPS-stimulated NPDFs.

\section{Discussion}

Seaweed has long been traditionally consumed for medicinal and dietary purposes. Marine algae are known to produce natural bioactive materials, such as dietary fibers, protein, polysaccharides, vitamins, minerals and various functional polyphenols (12). They are rich sources of anti-inflammatory therapeutic agents. A pro-inflammatory response is initiated as a defense reaction following stimulation by environmental stimuli such as pathogens and damage, resulting in the expression of pro-inflammatory mediators. These pro-inflammatory factors are regarded as responsible for the pathological states associated with NPs (4). Therefore, the present study was attempted to examine the pharmacological effects of DDE on the expression of inflammatory cytokines and the migration of neutrophils. In addition, the mechanism of action of PA-LPS-induced stimulation of NPDFs was investigated.

Inflammatory factors are expressed in response to gramnegative bacterial infections, mediated by LPS, a cell wall component of gram-negative bacteria. LPS is a pathogenassociated molecular pattern that provokes pathogenicity. Fibroblasts are the major structural components of tissues and play an augmenting effector role in the inflammatory response (13). Nasal fibroblasts are the principal structural components of the nose and are involved in NPs, which are common findings in chronic rhinosinusitis (14). Nasal fibroblasts produce pro-inflammatory cytokines, including IL-6, and chemokines, including IL-8, in nasal fibroblasts upon LPS stimulation (3).

We first investigated $P A$-LPS-induced production of IL-6 and IL-8 in HNDFs. IL-6, a pleiotropic cytokine, has a wide range of biological activity, which is associated with the production of acute phase proteins. IL-6 is associated with the pathogenesis of diverse inflammatory diseases, including multiple myeloma, rheumatoid arthritis, Crohn's disease, 

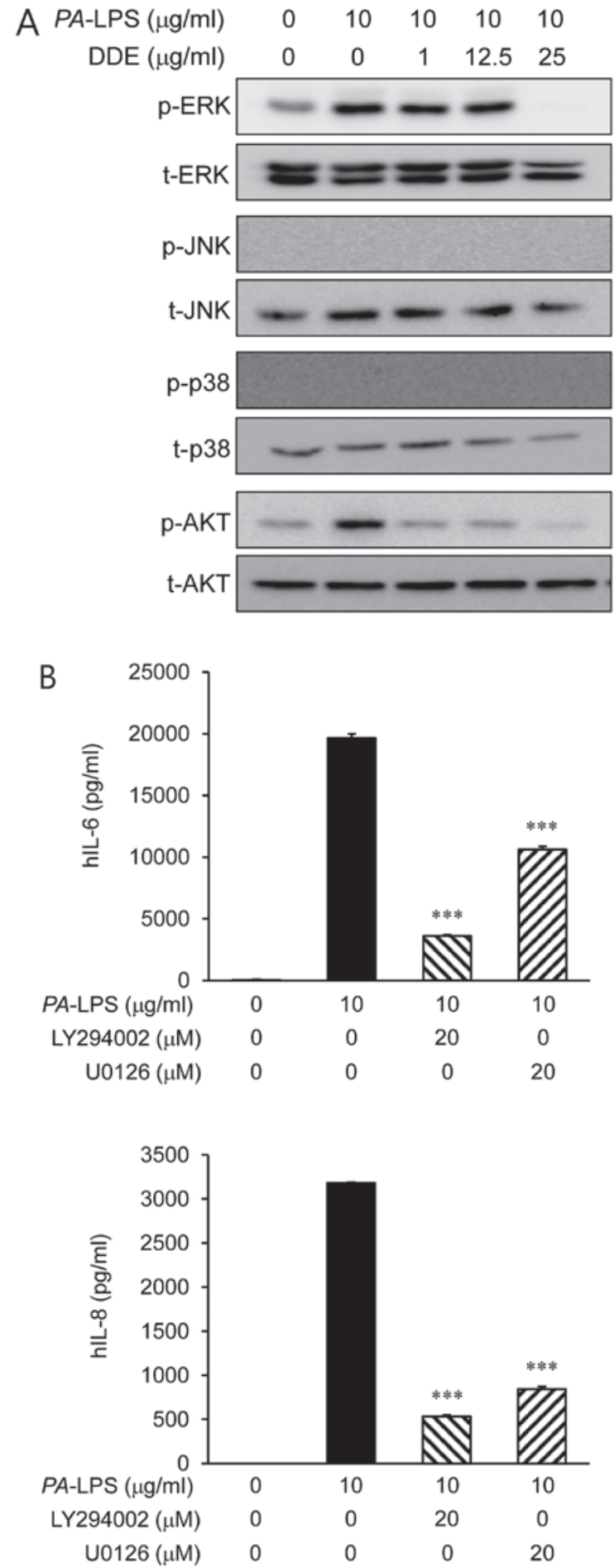

Figure 4. Effect of Distromium decumbens (DDE) on Pseudomonas aeruginosa-lipopolysaccharide (PA-LPS)-induced phosphorylation of MAPKs and Akt in nasal polyp-derived fibroblasts (NPDFs). (A) NPDFs were treated with a vehicle or the indicated concentrations of DDE for $1 \mathrm{~h}$ prior to stimulation with $P A$-LPS $(10 \mu \mathrm{g} / \mathrm{ml})$ for $2 \mathrm{~h}$. Cell extracts were then prepared and subjected to western blotting with antibodies specific to the phosphorylated forms of extracellular signal-related kinase (ERK), c-Jun N-terminal kinase (JNK), p38 and Akt. The results presented are representative of three independent experiments. (B) The expression levels of interleukin-6 (IL-6) and IL-8 in the culture medium were determined by enzyme-linked immunosorbent assay (ELISA). NPDFs were treated with LY294002 (an Akt inhibitor) and U0126 (an ERK inhibitor) 30 min before PA-LPS stimulation for $24 \mathrm{~h}$.

asthma and lupus (15-18). IL-6-induced signaling can be mostly seen in a relatively stingy number of IL-6-reactive cells,

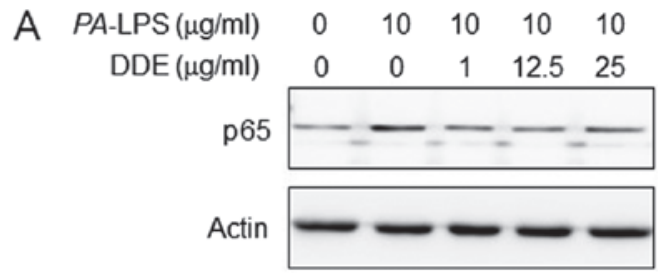

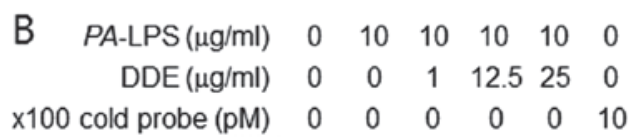
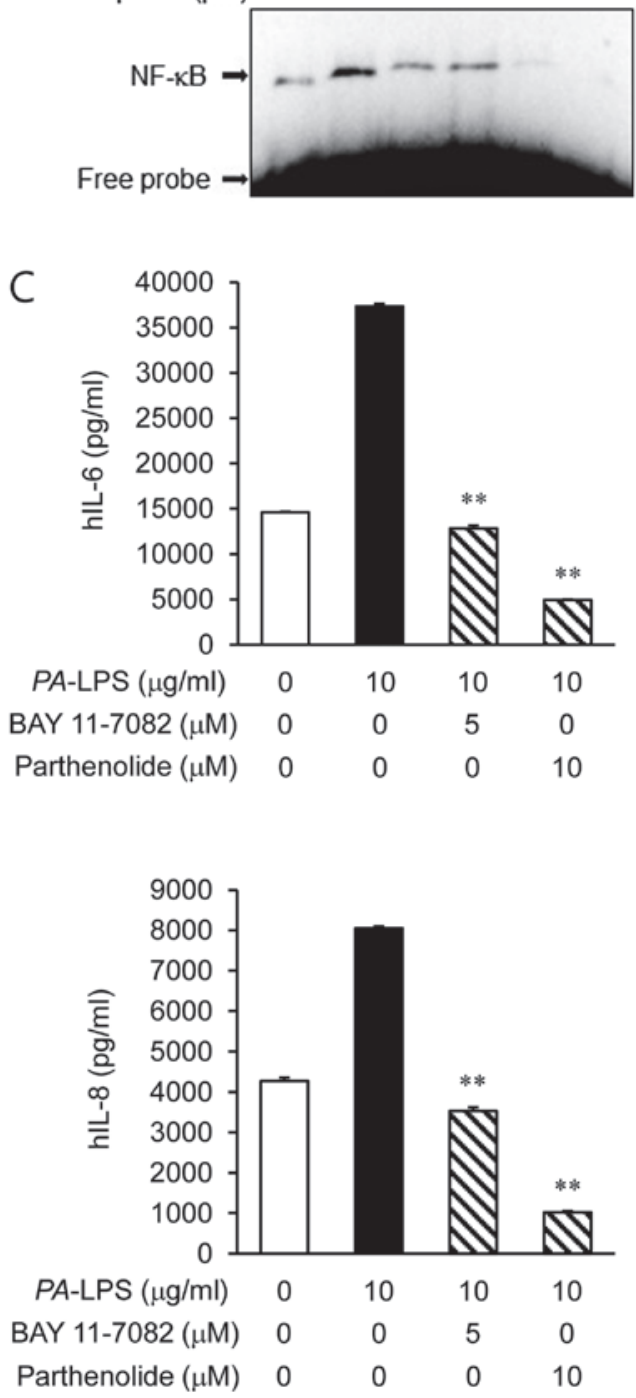

Figure 5. Effect of Distromium decumbens (DDE) on the translocation and binding of nuclear factor- $\kappa \mathrm{B}(\mathrm{NF}-\kappa \mathrm{B})$ into the nuclei of Pseudomonas aeruginosa-lipopolysaccharide ( $P A$-LPS)-stimulated nasal polyp-derived fibroblasts (NPDFs). The NPDFs were pretreated with DDE (1, 12.5 or $25 \mu \mathrm{g} / \mathrm{ml}$ ) for $1 \mathrm{~h}$ and then stimulated with PA-LPS for $2 \mathrm{~h}$. (A) Nuclear extracts were evaluated for $N F-\kappa B$ via western blot analysis. (B) Nuclear extracts were evaluated for $\mathrm{NF}-\kappa \mathrm{B}$ via electrophoretic mobility shift assay (EMSA). (C) The production of interleukin-6 (IL-6) and IL-8 was measured using an enzyme-linked immunosorbent assay (ELISA) kits. NPDFs were pretreated with NF- $\mathrm{NB}$ inhibitors, BAY 11-7082 or parthenolide, for $30 \mathrm{~min}$, and were then stimulated with $P A$-LPS for 24 h. ${ }^{* *} \mathrm{P}<0.01$ vs. $P A$-LPS-stimulated values.

whereas in a chronic inflammatory phase it is able to activate nearly all cells of the body (19). A recent study confirmed elevated IL-6 protein expression in polyp tissue compared to its expression in middle turbinate in the same patients with 
CRS with NPs (CRSwNP) (20). These results suggest that IL-6 plays a pathogenic role in CRSwNP. Although IL-8 synthesis aims at combating and eliminating the pathogen, persistent production of IL-8 plays a crucial role in the accumulation of neutrophils in sites of inflammation (21). The concentrations of IL-6 and IL-8 are increased in nasal lavage and NPs in CRS, and they activate NP growth (22). As shown in Fig. 2 DDE inhibited the PA-LPS-induced production of IL- 6 and IL-8 at concentrations of DDE that were not cytotoxic to the NPDFs. Next, we performed functional validation by assessing the attenuation effect of DDE on the migration of neutrophils in vitro. Neutrophils release matrix metalloproteinases and induce tissue destruction $(23,24)$. Because fibroblasts can produce a variety of chemokines, they are considered responsible for local recruitment of inflammatory cells $(25,26)$. A human promyelocytic HL-60 cell line that can be induced to differentiate using agents such as DMSO is a useful model system for studying neutrophil migration (27). We therefore used dHL-60 cells to evaluate the anti-migratory effects of DDE. Fig. 3 shows that treatment of dHL-60 cells with DDE $(1,12.5$ or $25 \mu \mathrm{g} / \mathrm{ml})$ decreased migration dose-dependently.

As DDE inhibited the expression of IL- 6 and IL- 8 in $P A$-LPS-stimulated NPDFs, we further investigated the mechanism underlying the inhibitory actions of DDE. LPS promotes the transcription of a variety of inflammatory genes related to inflammatory responses, including MAPKs (ERK, JNK and p38 MAPK) and the Akt pathway, in various types of cells (28). MAPKs play an important role in the control of cell responses. MAPKs have been implicated as important mediators of the signaling pathway that appears to play a critical role in the inflammatory response (29). In addition, Akt is essential in LPS-stimulated inflammation progression (30), since LPS induces inflammatory responses via Akt signaling in fibroblasts (31). Therefore, modulation of the Akt axis is considered to be an effective approach towards the treatment of many inflammatory disorders. A previous study demonstrated that LPS stimulates IL-6 and IL-8 expression through the MAPK and Akt signaling pathways in NPDFs (4). As expected, when NPDFs were treated with PA-LPS, ERK and Akt were phosphorylated, whereas pretreatment with DDE significantly reduced the LPS-induced phosphorylation of ERK and Akt (Fig. 4A). In addition, treatment with these kinase inhibitors effectively inhibited PA-LPS-stimulated expression of IL-6 and IL-8 (Fig. 4B). Therefore, the present study demonstrated a significant inhibition of $P A$-LPS-stimulated phosphorylation of ERK and Akt by DDE in NPDFs.

Transcription factor $\mathrm{NF}-\kappa \mathrm{B}$ is known to be a multifunctional regulator of various genes involved in the expression of many inflammatory mediators involved in inflammatory process (32). Activation of $\mathrm{NF}-\kappa \mathrm{B}$ causes phosphorylation, ubiquitination and proteasome-mediated degradation of the inhibitory I $\kappa \mathrm{B}$ proteins and then nuclear transfer (33). Therefore, we examined the effects of DDE on the PA-LPS-stimulated activation of $N F-\kappa B$ by NPDFs. Since activated $N F-\kappa B$ enters the nucleus and induces IL-6 and IL-8 expression, we studied the nuclear translocation of the NF- $\kappa \mathrm{B}$ subunit. Western blot analysis showed that stimulation with PA-LPS induced translocation of $\mathrm{NF}-\kappa \mathrm{B}$ to the nuclear compartment. However, nuclear translocation of PA-LPS-induced NF- $\mathrm{NB}$ was attenuated in the presence of DDE. According to EMSA data, $P A$-LPS stimulation increased the DNA-binding activity

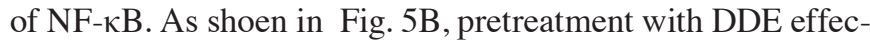
tively inhibited the $P A$-LPS-stimulated DNA-binding activity of NF- $\kappa$ B. To confirm the above results, we investigated the effects of the NF- $\kappa$ B inhibitors, BAY 11-7082 and parthenolide, on the $P A$-LPS-induced production of IL- 6 and IL- 8 by NPDFs (Fig. 5C). These data demonstrated that DDE inhibits $\mathrm{NF}-\kappa \mathrm{B}$ activity in $P A$-LPS-stimulated NPDFs by suppressing the nuclear translocation of p65, resulting in attenuation of IL-6 and IL-8 production.

In conclusion, the results of the present study demonstrated that PA-LPS increased the release of IL- 6 and IL- 8 from cultured NPDFs. Pretreatment with DDE significantly attenuated the expression of IL- 6 and IL- 8 in NPDFs under PA-LPS stimulated inflammatory conditions by suppressing the activation of the ERK, Akt, and NF- $\mathrm{BB}$ signaling pathways. These results suggest that the anti-inflammatory activity of bioactive compounds contained in D. decumbens ethanolic bioactive extract have the potential to be developed as therapeutic agents for the management of NPs.

\section{Acknowledgements}

This study was supported by the National Marine Biodiversity Institute of Korea Research program (no. 2017M01400).

\section{References}

1. Pawankar R: Nasal polyposis: an update: editorial review. Curr Opin Allergy Clin Immunol 3: 1-6, 2003.

2. Chaaban MR, Walsh EM and Woodworth BA: Epidemiology and differential diagnosis of nasal polyps. Am J Rhinol Allergy 27: 473-478, 2013.

3. Cho JS, Han IH, Lee HR and Lee HM: Prostaglandin $\mathrm{E}_{2}$ induces IL- 6 and IL- 8 production by the EP receptors/Akt/NF- $\mathrm{BB}$ pathways in nasal polyp-derived fibroblasts. Allergy Asthma Immunol Res 6: 449-457, 2014.

4. Cho JS, Kang JH, Um JY, Han IH, Park IH and Lee HM: Lipopolysaccharide induces pro-inflammatory cytokines and MMP production via TLR4 in nasal polyp-derived fibroblast and organ culture. PLoS One 9: e90683, 2014.

5. Meyer JE, Harder J, Görögh T, Schröder JM and Maune S: hBD-2 gene expression in nasal mucosa. Laryngorhinootologie 79: 400-403, 2000 (In German).

6. Harris JF, Aden J, Lyons CR and Tesfaigzi Y: Resolution of LPS-induced airway inflammation and goblet cell hyperplasia is independent of IL-18. Respir Res 8: 24, 2007.

7. Lee DS, Park WS, Heo SJ, Cha SH, Kim D, Jeon YJ, Park SG, Seo SK, Choi JS, Park SJ, et al: Polyopes affinis alleviates airway inflammation in a murine model of allergic asthma. J Biosci 36 : 869-877, 2011.

8. Athukorala Y, Jung WK, Park PJ, Lee YJ, Kim SK, Vasanthan T, No HK and Jeon YJ: Evaluation of biomolecular interactions of sulfated polysaccharide isolated from Grateloupia filicina on blood coagulation factors. J Microbiol Biotechnol 18: 503-511, 2008.

9. Kim TH, Ko SC, Oh GW, Park HH, Lee DS, Yim MJ, Lee JM, Yoo JS, Kim CS, Choi IW, et al: Studies on bioactive substances and antioxidant activities of marine algae from Jeju Island. J Mar Biosci Biotechnol 8: 30-38, 2016

10. Meltzer EO, Hamilos DL, Hadley JA, Lanza DC, Marple BF Nicklas RA, Adinoff AD, Bachert C, Borish L and Chinchilli VM; Rhinosinusitis initiative: Rhinosinusitis: Developing guidance for clinical trials. Otolaryngol Head Neck Surg 135 (Suppl 5): S31-S80, 2006

11. Paeng SH, Park WS, Jung WK, Lee DS, Kim GY, Choi YH, Seo SK, Jang WH, Choi JS, Lee YM, et al: YCG063 inhibits Pseudomonas aeruginosa LPS-induced inflammation in human retinal pigment epithelial cells through the TLR2-mediated AKT/NF-kB pathway and ROS-independent pathways. Int J Mol Med 36: 808-816, 2015. 
12. Jung WK, Choi I, Oh S, Park SG, Seo SK, Lee SW, Lee DS, Heo SJ, Jeon YJ, Je JY, et al: Anti-asthmatic effect of marine red alga (Laurencia undulata) polyphenolic extracts in a murine model of asthma. Food Chem Toxicol 47: 293-297, 2009.

13. Flavell SJ, Hou TZ, Lax S, Filer AD, Salmon M and Buckley CD: Fibroblasts as novel therapeutic targets in chronic inflammation. Br J Pharmacol 153 (Suppl 1): S241-S246, 2008.

14. Carroll WW, O'Connell BP, Schlosser RJ, Gudis DA, Karnezis TT, Lawrence LA, Soler ZM and Mulligan JK: Fibroblast levels are increased in chronic rhinosinusitis with nasal polyps and are associated with worse subjective disease severity. Int Forum Allergy Rhinol 6: 162-168, 2016.

15. Houssiau FA, Devogelaer JP, Van Damme J, de Deuxchaisnes CN and Van Snick J: Interleukin-6 in synovial fluid and serum of patients with rheumatoid arthritis and other inflammatory arthritides. Arthritis Rheum 31: 784-788, 1988.

16. Atreya R, Mudter J, Finotto S, Müllberg J, Jostock T, Wirtz S, Schütz M, Bartsch B, Holtmann M, Becker C, et al: Blockade of interleukin 6 trans signaling suppresses T-cell resistance against apoptosis in chronic intestinal inflammation: Evidence in crohn disease and experimental colitis in vivo. Nat Med 6: 583-588, 2000.

17. Doganci A, Eigenbrod T, Krug N, De Sanctis GT, Hausding M, Erpenbeck VJ, Haddad B, Lehr HA, Schmitt E, Bopp T, et al: The IL-6R $\alpha$ chain controls lung $\mathrm{CD} 4{ }^{+} \mathrm{CD} 25^{+}$Treg development and function during allergic airway inflammation in vivo. J Clin Invest 115: 313-325, 2005.

18. Polgár A, Brózik M, Tóth S, Holub M, Hegyi K, Kádár A Hodinka L and Falus A: Soluble interleukin-6 receptor in plasma and in lymphocyte culture supernatants of healthy individuals and patients with systemic lupus erythematosus and rheumatoid arthritis. Med Sci Monit 6: 13-18, 2000.

19. Allocca M, Jovani M, Fiorino G, Schreiber S and Danese S: Anti-IL-6 treatment for inflammatory bowel diseases: Next cytokine, next target. Curr Drug Targets 14: 1508-1521, 2013.

20. Peters AT, Kato A, Zhang N, Conley DB, Suh L, Tancowny B Carter D, Carr T, Radtke M, Hulse KE, et al: Evidence for altered activity of the IL-6 pathway in chronic rhinosinusitis with nasal polyps. J Allergy Clin Immunol 125: 397-403.e10, 2010.

21. Zimmermann HW, Seidler S, Gassler N, Nattermann J, Luedde T, Trautwein C and Tacke F: Interleukin- 8 is activated in patients with chronic liver diseases and associated with hepatic macrophage accumulation in human liver fibrosis. PLoS One 6: e21381, 2011.
22. Kim JA, Cho JH, Park IH, Shin JM, Lee SA and Lee HM: Diesel exhaust particles upregulate interleukins IL-6 and IL-8 in nasal fibroblasts. PLoS One 11: e0157058, 2016.

23. Romanic AM, White RF, Arleth AJ, Ohlstein EH, Barone FC and Dawson VL: Matrix metalloproteinase expression increases after cerebral focal ischemia in rats: Inhibition of matrix metalloproteinase-9 reduces infarct size. Stroke 29: 1020-1030, 1998.

24. Salamonsen LA: Current concepts of the mechanisms of menstruation: A normal process of tissue destruction. Trends Endocrinol Metab 9: 305-309, 1998.

25. Kawka E, Witowski J, Fouqet N, Tayama H, Bender TO, Catar R, Dragun D and Jörres A: Regulation of chemokine CCL5 synthesis in human peritoneal fibroblasts: A key role of IFN- $\gamma$. Mediators Inflamm 2014: 590654, 2014.

26. Xia Y, Entman ML and Wang Y: CCR2 regulates the uptake of bone marrow-derived fibroblasts in renal fibrosis. PLoS One 8: e77493, 2013.

27. Millius A and Weiner OD: Chemotaxis in neutrophil-like HL-60 cells. Methods Mol Biol 571: 167-177, 2009.

28. Intayoung P, Limtrakul P and Yodkeeree S: Antiinflammatory Activities of crebanine by inhibition of NF- $\kappa$ B and AP-1 activation through suppressing MAPKs and Akt signaling in LPS-induced RAW264.7 macrophages. Biol Pharm Bull 39: 54-61, 2016.

29. Kaminska B: MAPK signalling pathways as molecular targets for anti-inflammatory therapy--from molecular mechanisms to therapeutic benefits. Biochim Biophys Acta 1754: 253-262, 2005.

30. Xu CQ, Liu BJ, Wu JF, Xu YC, Duan XH, Cao YX and Dong JC: Icariin attenuates LPS-induced acute inflammatory responses: Involvement of PI3K/Akt and NF-kappaB signaling pathway. Eur J Pharmacol 642: 146-153, 2010.

31. Wang QB, Sun LY, Gong ZD and Du Y: Veratric acid inhibits LPS-induced IL-6 and IL-8 production in human gingival fibroblasts. Inflammation 39: 237-242, 2016.

32. Wang YB, Tan B, Mu R, Chang Y, Wu M, Tu HQ, Zhang YC, Guo SS, Qin XH, Li T, et al: Ubiquitin-associated domaincontaining ubiquitin regulatory $\mathrm{X}(\mathrm{UBX})$ protein $\mathrm{UBXN1}$ is a negative regulator of nuclear factor $\kappa \mathrm{B}(\mathrm{NF}-\kappa \mathrm{B})$ signaling. J Biol Chem 290: 10395-10405, 2015

33. De Bosscher K, Vanden Berghe W and Haegeman G: The interplay between the glucocorticoid receptor and nuclear factor-kappaB or activator protein-1: Molecular mechanisms for gene repression. Endocr Rev 24: 488-522, 2003. 